\title{
Energy Efficient Active Vibration Damping
}

\author{
E. Zaev , G. Rath* , and H. Kargl ${ }^{* *}$ \\ Faculty of mechanical engineering, Ss. Cyril and Methodius University, Skopje, Macedonia \\ E-mail: emil.zaev@mf.edu.mk, gerhard.rath@unileoben.ac.at,hubert.kargl@ sandvik.com \\ *Institute for automation, University of Leoben, Leoben, Austria \\ ** Sandvik Mining and Construction, Austria
}

\begin{abstract}
Mining machines are subjected to severe vibrations during their operation. If we succeed to damp some of those vibrations then we have succeed to reduce the dynamic load of the machine and to improve operator comfort and productivity. The main idea for the research done in this paper is to investigate possible improvements in active vibration damping in hydraulic power systems of a mobile machine (mining machine) influencing hydraulic system layout and control strategy. Modelling of a standard and individual metering (separate meter-in separate meter-out SMISMO) load sensing (LS) hydraulic power system of a machine has been done. Model of the individual metering system has been validated with measurements. Those models have been used to study new concepts of active vibration damping. SMISMO system has been used to develop new energy efficient concept for active vibration damping using the third (crossport) valve between meter-in and meter-out lines of the hydraulic cylinder as a damping element. Using simulations has been shown that this new system can improve damping effect, drastically decreasing usage of the energy from the pump.

Keywords: fluid power systems, active vibration damping, dynamic pressure feedback, energy efficiency.
\end{abstract}

\section{Introduction}

The vibrations, which are appearing during working process of the mining machine and are a result from external forces are part of this study. Dampening of those vibrations can be accomplished in two ways. The first way is with passive damping. Passive damping is usually done with the usage of high pressure hydro-pneumatic accumulators [1], [2]. The advantage of this system is that no energy from the pump is used for dampening the vibrations, which makes this system energy efficient. The disadvantage is additional costs, place and maintenance of the high pressure accumulators.

A second way to damp the vibrations on the machine is to use active vibration damping [3], [4], [5], [6], [7]. Active vibration damping is not an energy efficient way for dampening the oscillations, since energy from the pump (or other external sources) is used to damp the oscillations. Still, this is an efficient way to damp the vibration, hence this method is attractive to automotive [8], [9], [10], [11], [12], [13], [14], [15], [16] and construction industry [17], [18], [19]. To damp the oscillations with active vibration dampening, some kind of oscillation source feedback is needed (acceleration feedback, pressure feedback or force feedback) to find out about dynamics of the sources. Then, energy from the pump is used to act against those forces, the proportional control valve is open and the fluid from the pump is brought in the chamber. The advantage of the active vibration damping is that the same means for controlling the motion (opening of the valve) can be used as well as for damping. Experimental work with using optimal control theory [20], [21], [22] has shown that there is a potential in making active vibration damping more energy efficient. Unfortunately, practical implementation of those principles is still an adventure.

Trends to improve the energy consumptions in heavy machinery are asking for change of the conventional valve system with individual metering systems. This gives possibility for energy regeneration and recuperation and effective deceleration control which leads to energy efficiency improvement of the machine [23-34]. However, the main idea of changing the classical LSPC system with SMISMO system at the SANDVIK machine (Figure 1) is to make the boom more stiff during the cutting process, controlling the pressure in the meter-out side of the active cylinder. The same system can also be used for active damping. Actual trends towards damping the oscillations of the machine structure is in the area of active oscillation damping technologies [35].

This research explores one simple method to introduce damping in hydraulic power systems for heavy machinery: dynamic pressure feedback (DPF). First, it is examined the influence of dynamic pressure feedback on the servo hydraulic system with load sensing pressure compensated (LSPC) system. Second, effects from dynamic pressure feedback on a individual metering hydraulic system are analysed. Third, novel 
energy efficient dynamic pressure feedback (EE DPF) is proposed.

\section{Model development}

The cutting process of a mining machine SANDVIK Roadheader MT720 (fig. 1) is done by the cutter head. The cutter head is moved in horizontal and vertical direction by hydraulic cylinders (fig. 17).

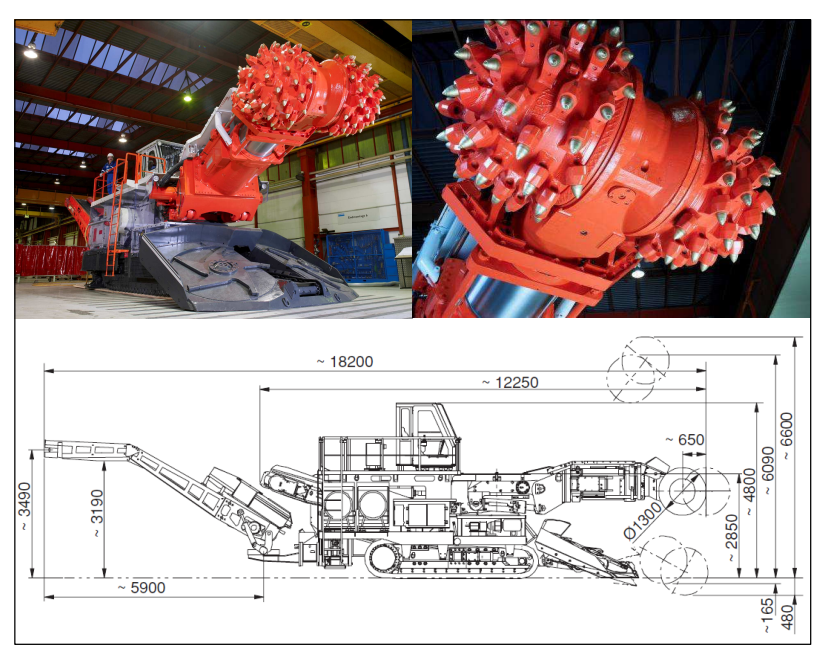

Figure 1: Mining Machine SANDVIK Roadheader MT720 [36].

Hydraulic system which is used in the machine is from LSPC type, as presented on fig. 11 .

\subsection{Model of the servovalve controlled actuator}

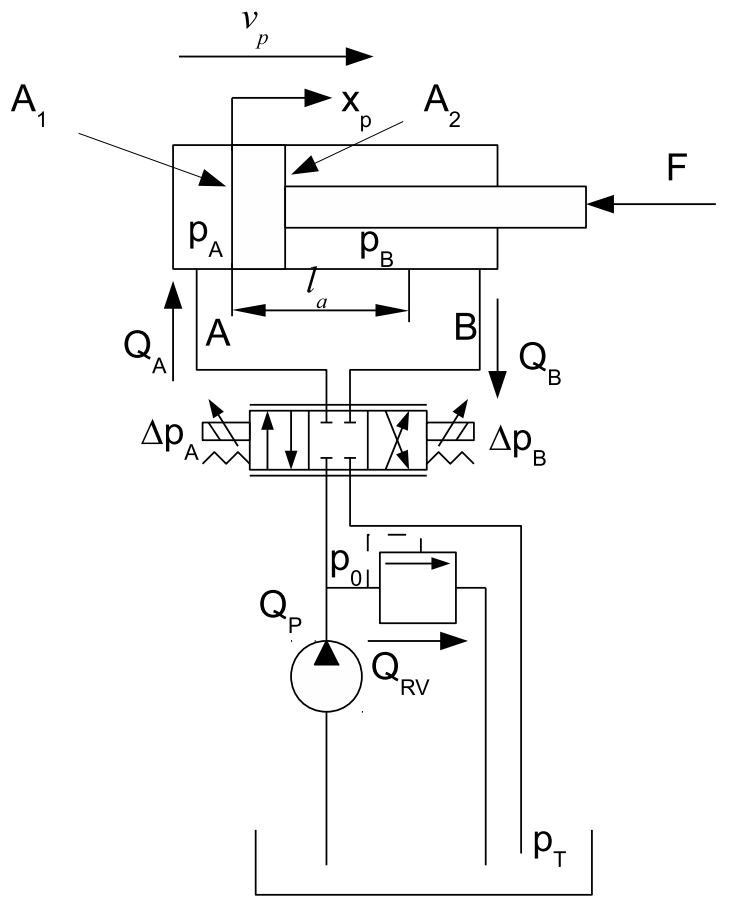

Figure 2: Hydraulic system, servovalve controlled cylinder.
Hydraulic actuators, actually hydraulic cylinders, do most important movements of cutter head during the cutting process. A hydraulic cylinder integrated in the turret (fig. 1) does horizontal movement. Two hydraulic cylinders placed underneath the turret actuate vertical movement and two cylinders on each side of the boom actuate the telescopic elongation.

The cylinder and its servovalve (fig. 2) are presented with non-linear equations derived from basic physical laws. The modelling is performed in graphical environment using Matlab/Simulink.

The dynamics of the valve which has been used in the hydraulic system can be represented with the following equations for standard second order system [37], [38]:

$$
G_{v}(s)=\frac{x_{v}}{U_{v}}=\frac{\omega_{v}{ }^{2}}{s^{2}+2 \cdot \delta_{v} \cdot \omega_{v} \cdot s+\omega_{v}{ }^{2}}
$$

Where $x_{v}$ is the valve spool displacement, $U_{v}$ is valve input voltage, $\omega_{v}$ is valve undamped natural frequency and $\delta_{v}$ is damping ratio coefficient.

Sign convention for cylinder piston displacement $x_{p}$ in all equations is chosen to be positive for cylinder elongation. This means that when cylinder is fully extended $x_{p}=l_{a}$. The rate of pressure increase in the rod and piston side of the cylinder can be described by the rate at which the fluid in the volume $\mathrm{V}$ of the chamber is being compressed $\left(\frac{d p}{d t}=\frac{E}{V} \frac{d V}{d t}\right)$ as:

$$
\begin{gathered}
\frac{d p_{A}}{d t}=\left(\frac{\beta_{e}}{V_{1}+A_{1} x_{p}}\right)\left(Q_{A}-A_{1} v_{p}\right) \\
\frac{d p_{B}}{d t}=\left(\frac{\beta_{e}}{V_{2}+A_{2}\left(l_{a}-x_{p}\right)}\right)\left(A_{2} v_{p}-Q_{B}\right)
\end{gathered}
$$

Where $V_{1}$ and $V_{2}$ are dead volumes in the cylinder and volume of the fluid in connected hoses, with the cylinder in retracted position.

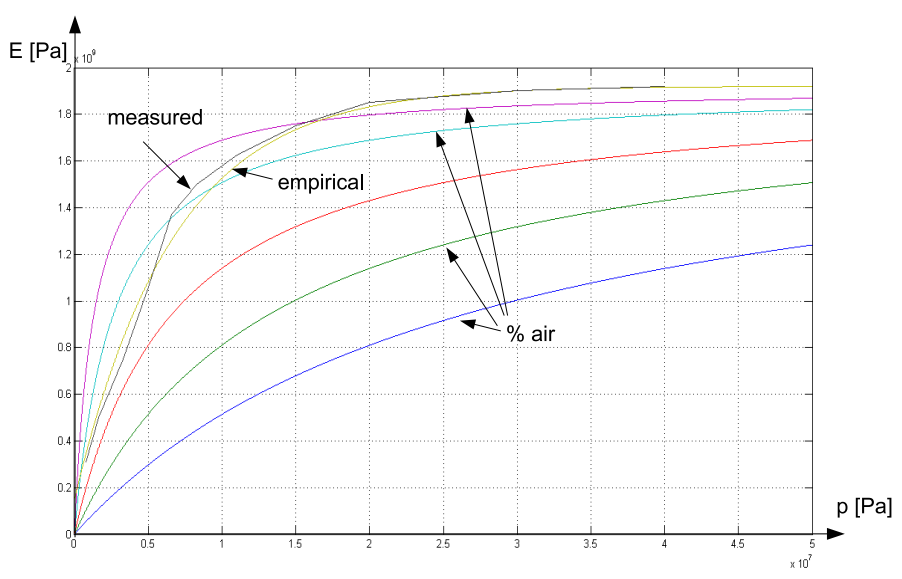

Figure 3: Measured and simulated values of an bulk modulus of the oil. Blue line has highest percentage of air.

It has been identified with comparison of measured and calculated values (fig. 3) that effective bulk modulus of the here used oil $\beta_{e}$ can be calculated with the empirical equation: 


$$
\beta_{e}(p)=\beta_{\max }\left[1-\exp \left(-k_{1}-k_{2} \cdot 10^{-7} \cdot p\right)\right][P a]
$$

Where coefficients $k_{1}, k_{2}$ and $\beta_{\max }$ have been identified to be $k_{1}=0.08, k_{2}=1.5$ and $\beta_{\max }=1.8 \cdot 10^{9}\left[P_{a}\right]$ for here used oil. In simulations, if ideal not air contaminated oil is assumed, $\beta=1.4 \cdot 10^{9}\left[P_{a}\right]$ can be used.

From Second Newton Low force on the cylinder may be described as:

$$
\begin{gathered}
a_{p}=\frac{d v_{p}}{d t}=\frac{\left(p_{A} A_{1}-p_{B} A_{2}-F_{f}-F_{e x t}\right)}{m_{p}} \\
\frac{d x_{p}}{d t}=v_{p}
\end{gathered}
$$

Where subscription $p$ is used for piston mass, displacement, speed and acceleration. Friction force $F_{f}$ can be approximated with only viscous friction and $F_{f}=B \cdot v_{p}$ where $B$ is friction coefficient.

Finally, to describe the flow through the valve, non-linear orifice equation has been used:

$$
\begin{gathered}
Q_{A}=Q_{N} \cdot \frac{y}{y_{\max }} \cdot \sqrt{\frac{\Delta p_{A}}{\Delta p_{N}}}={ }_{N} \cdot \frac{y}{y_{\max }} \cdot \sqrt{\frac{p_{0}-p_{A}}{\Delta p_{N}}} \\
Q_{B}=Q_{N} \cdot \frac{y}{y_{\max }} \cdot \sqrt{\frac{\Delta p_{B}}{\Delta p_{N}}}=Q_{N} \cdot \frac{y}{y_{\max }} \cdot \sqrt{\frac{p_{B}-p_{T}}{\Delta p_{N}}}
\end{gathered}
$$

Where $Q_{N}, y_{\max }$ and $\Delta p_{N}$ are nominal valve parameters.

\subsection{Model of the vertical mechanical structure}

Vertical mechanical structure is given on fig. 4

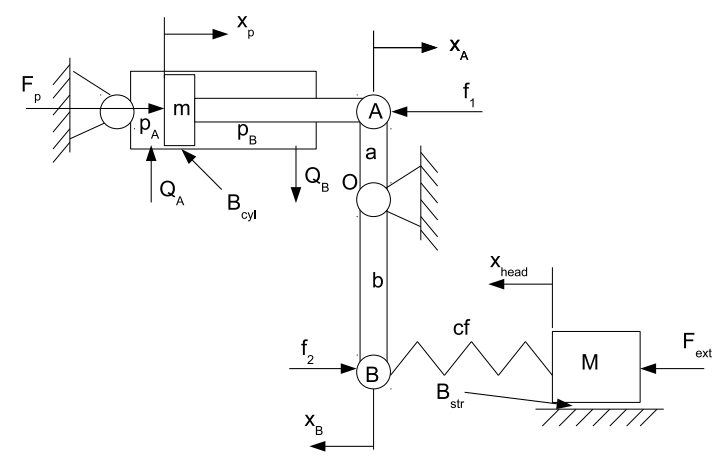

Figure 4: Simplified model of the vertical hydro-mechanical system.

Differential equations which describe the dynamic behaviour of the vertical hydro - mechanical structure are as follows:

$$
\begin{gathered}
\left(m D^{2}+B_{p} D\right) x_{p}(t)=F_{p}-f_{1} \\
x_{B}(t) \cdot c_{f}+x_{\text {head }}(t) \cdot c_{f}=f_{2} \\
\left(m D^{2}+B_{\text {str }} D+c_{f}\right) x_{\text {head }}(t)-c_{f} x_{B}(t)=F_{\text {ext }} \\
\frac{f_{1}}{f_{2}}=\frac{x_{B}}{x_{A}}=\frac{b}{a}=i
\end{gathered}
$$

Or, translated in "s" domain:

$$
\begin{gathered}
x_{p}(s)=\frac{1}{m} \frac{1}{s^{2}}\left\{F_{p}-B \cdot x_{p}(s) \cdot s-\left[\left(x_{p}(s) \cdot i-x_{\text {head }}(s)\right) c_{f}\right] \cdot i\right\} \\
x_{\text {head }}(s)=\frac{1}{M} \frac{1}{s^{2}}\left\{F_{\text {ext }}-B \cdot x_{\text {head }}(s) \cdot s-\left[\left(x_{\text {cyl }}(s) \cdot i-x_{\text {head }}(s)\right) c_{f}\right]\right\}
\end{gathered}
$$

\subsection{Model of the horizontal mechanical structure}

Horizontal mechanical structure together with hydraulic system is given on fig. 5. Simplified model of this structure is given on fig. 6

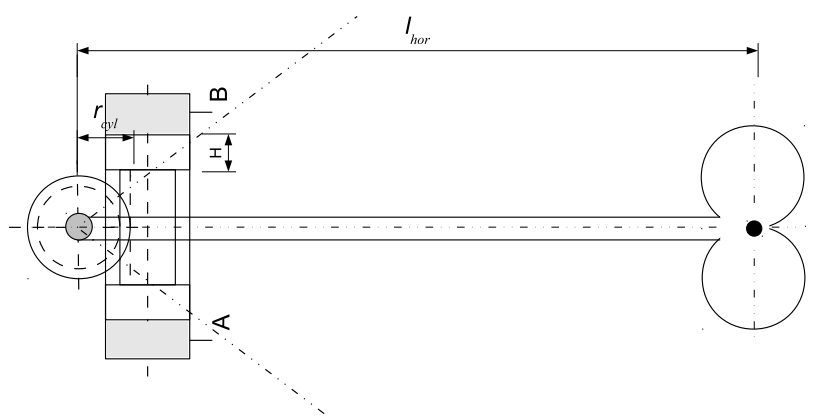

Figure 5: Horizontal hydro-mechanical system. Rodless cylinder (integrated in the turret) and boom with the cutter head.

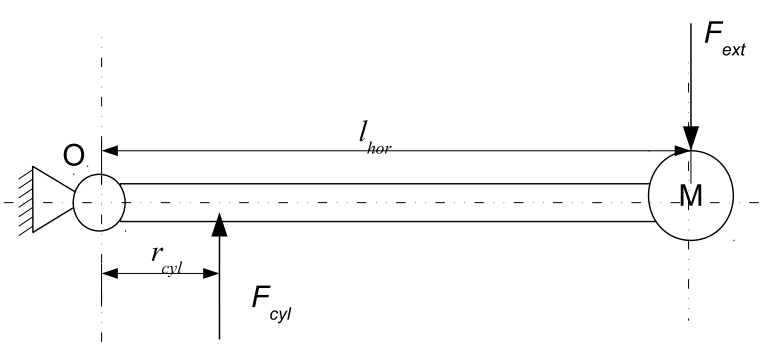

Figure 6: Simplified model of the horizontal structure.

Figure 6 shows haw the rodless cylinder is used for operation of a mechanical arm. The total mass of the moving arm is $M$. The distance from the gravity center of the mass to the joint $(O)$ is $l_{h o r}$. The lever length for the hydraulic cylinder is $r_{c y l}$.

Differential equations which describe dynamic behaviour of the horizontal mechanical system are given as follows:

$$
\begin{aligned}
& J_{h o r} \cdot \ddot{\theta}+B_{T} \cdot \dot{\theta}=F_{p} \cdot r_{c y l}-F_{\text {ext }} \cdot l_{\text {hor }} \\
& \ddot{\theta}=\frac{\ddot{x}}{r_{c y l}} \\
& \dot{\theta}=\frac{\dot{x}}{r_{c y l}}
\end{aligned}
$$

In addition, in "s" domain:

$$
\theta(s)=\frac{1}{J_{h o r}} \frac{1}{s^{2}}\left(F_{p} \cdot r_{c y l}-F_{e x t} \cdot l_{h o r}-B_{T} \cdot \theta \cdot s\right)
$$




\subsection{Model of the pump}

The pump used in the machine is from the LS type. Due to the lack of information for dynamic behaviour of the pump, and because the pump is not under examination but the rest of hydraulic system, the pump can be modelled as ideal load sensing pump. Let us imagine ideal LS pump as pump which always delivers required $\Delta p$ pressure from the highest load in the hydraulic circuit, or:

$$
p_{0}=p_{L S}+\Delta p
$$

where $p_{0}$ represents the pressure delivered from the pump and $p_{L S}$ represents pressure in the load sensing line. To make the model more realistic, the dynamics of the LS line can been taken in account with first order low pass filter $\left(\frac{\omega_{L S}}{s+\omega_{L S}}\right)$, designed so that it does not bring instabilities. This can be done in order to check the behaviour of the rest of the system when the LS pump is appropriately chosen and installed, as it is the case with the Roadheader. Good model of LS pump can be found in [39].

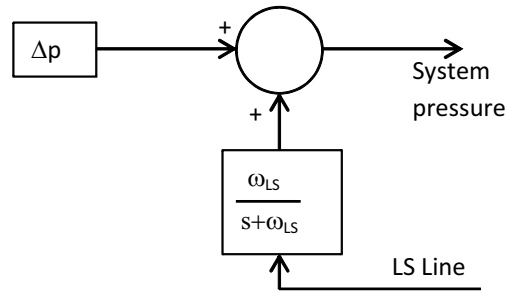

Figure 7: Model of the LS pump.

\subsection{Valve model adaptation to be used in individual metering system}

Special property of SMISMO systems is possibility to control two system parameters, in our case speed of the moving actuator and the pressure in the cylinder chambers. To accomplish this, our individual metering system uses two valves, one on the meter-in and one on the meter-out side. Model of the valve developed in Simulink must adequately represent this special property. Valve in our Simulink model of the individual metering system is modelled with two spools (left and right proportional valve), and has two separate control voltage $y_{A}$ and $y_{B}$. Voltage $y_{A}$ has been used to produce flow to the chamber $\mathrm{A}\left(Q_{A}\right)$, and voltage $y_{B}$ is used to produce the $Q_{B}$ flow. This model is presented on the fig. 8

\subsection{Model validation}

The model validation can be seen on fig. 9 and fig. 10. Figure 9 shows $24[s]$ pressure measurement done on the horizontal hydraulic SMISMO system during cutting process of the machine in comparison with simulated pressures. Input for simulations is external force modelled from measurements on cylinder pressures. In measurements and in simulation PI controller has been used to control back pressure (on the figure pressure $p_{B}$ ). On fig. 9 we can see very good matching of the pressures in meter-in side $\left(p_{A}\right)$. This can be expected

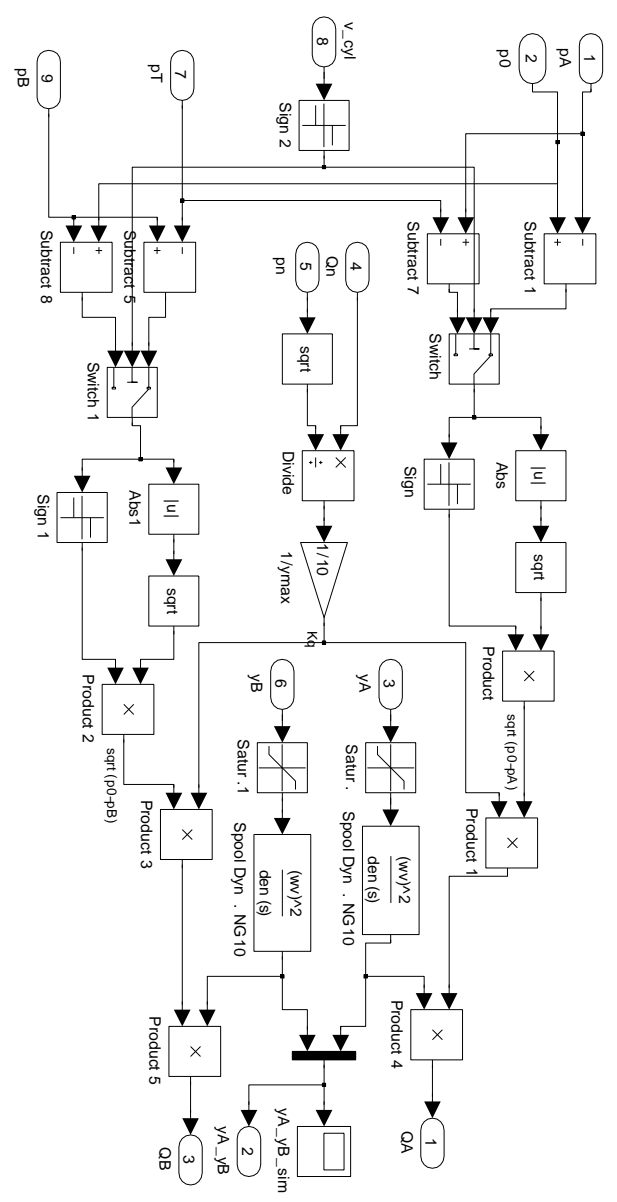

Figure 8: Simulink model of the separate metering system with two valves.

since in measurements and in simulations the opening of the meter-in valve was hold constant (it does not depend from sensor signals). Also, it can be noticed that simulated and measured pressures on the meter-out side $\left(p_{B}\right)$ are not matching perfectly. Simulated pressures have smoother values (they are more attenuated) and never go to cavitation. This also is not unusual since in simulations the feedback sensor signal and PI controller are idealized. Simulated and measured values of the horizontal angle of the boom are represented on the fig. 10 and have good confirmation.

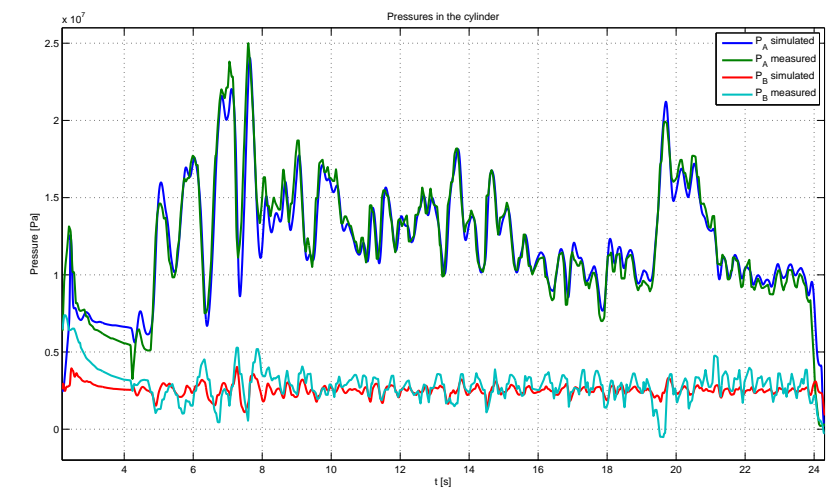

Figure 9: SMISMO model validation. Simulated and measured pressures in cylinder. 


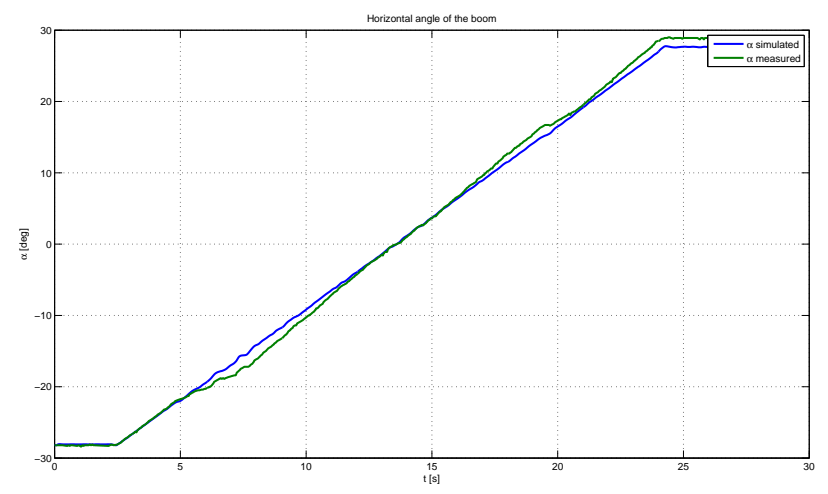

Figure 10: SMISMO model validation. Simulated and measured angle of the boom.

\section{Active vibration damping with hydraulic servo system}

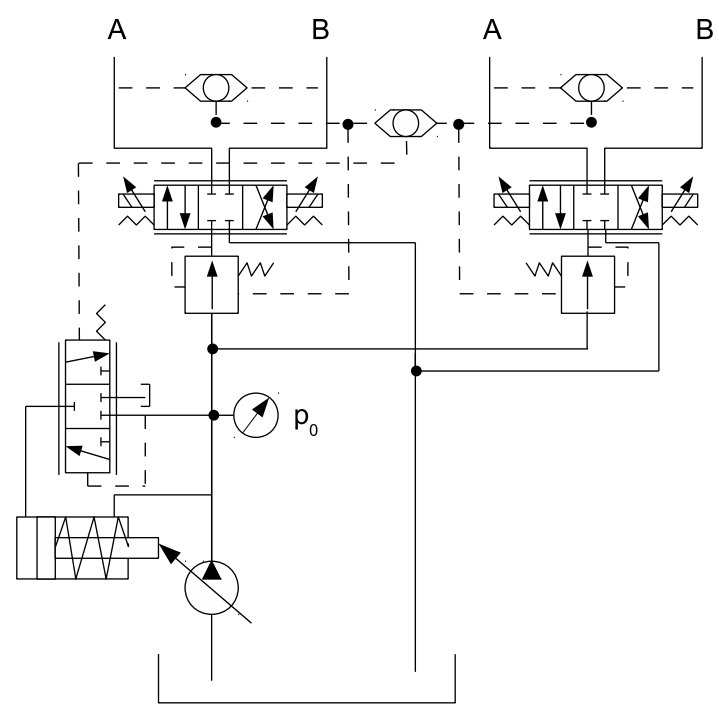

Figure 11: Load sensing pressure compensated systems.

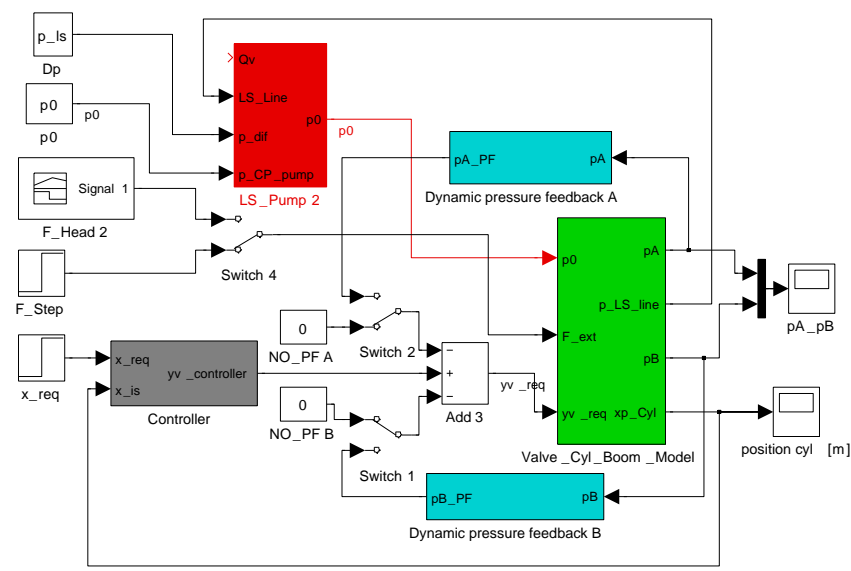

Figure 12: Simulink model of the hydro-mechanical LSPC system.

Investigations on possible damping with dynamic pressure feedback have been done for servo hydraulic system of LSPC

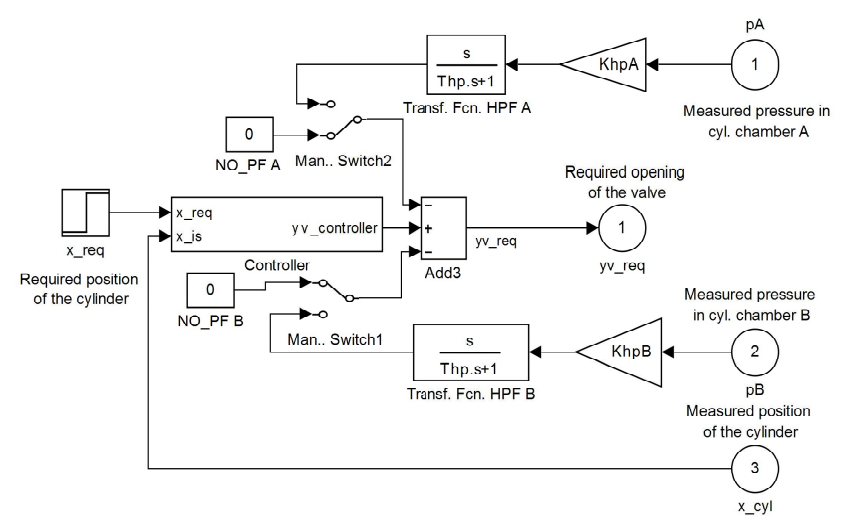

Figure 13: Implementation of the high pass filter in the pressure feedback lines.

type shown on fig. 11. Figure 12 shows the model of this system together with the high pass filter in the pressure feedback lines. Figure 13 zooms out implementation of the high pass filter in the pressure feedback lines. This model has been used to investigate the influence of the dynamic pressure feedback in three cases: (1) if implemented on meter-in (high pressure side), (2) if implemented on meter-out (low pressure side) and (3) if implemented on both sides. It has been determined that the introduction of dynamic pressure feedback on both sides has no advantages. Actually, the introduction of dynamic pressure feedback on the meter-in side (high pressure side) has the biggest influence and contributes to the attenuation of the pressure vibrations on the meter-out side also. That happens because two pressures are coupled through the piston. This also has been reported from other scientists [40]. The idea of using dynamic pressure feedback is that the feedback signal reaches its maximum value at a frequency, which has to be damped (the hydraulic frequency $\omega_{h}$ ). In the design of the high pass filter two conditions has been followed:

First, the cut-off frequency of the filter $\omega_{h p}=\frac{1}{T_{h p}}$ is set to be below the resonance frequency of the system [3], [40]. For our system it is chosen to be $\omega_{h p}=10\left[\mathrm{~s}^{-1}\right] ; T_{h p}=$ $\frac{1}{\omega_{h p}}=\frac{1}{10}=0.1[\mathrm{~s}]$.

Second, the feedback gain $K_{h p}$ is set to obtain reasonable stability margins [40]. Using this principle the value of $K_{h p}$ has been determinate to be $K_{h p}=0.00000007$.

To investigate the influence of dynamic pressure feedback on vibration damping, the eq. (5) has been changed, actually the friction $B$ in the mechanical structure has been neglected. This has been done with the purpose to see more clearly the influence of dynamic pressure feedback on vibration damping. Investigations of the implementation of dynamic pressure feedback on the meter-in side have been done with the following scenario:

The cutting head is moved using the vertical cylinder to reach $400 \mathrm{~mm}$ displacement from the starting position (see fig. 14 note vertical axis is in $[m]$ ). Simple position feedback and a proportional controller is used to track the position. The desired position is reached in approximately $20 \mathrm{~s}$ when the 
force of $50 \mathrm{kN}$ is applied in the positive direction (restrictive force). The vibrations in the system can be monitored trough the pressure sensors on the cylinder and are shown on fig. 15 and fig. 16). On the fig. 15 the pressure oscillations without dynamic pressure feedback are shown and on the fig. 16 the pressure oscillations with dynamic pressure feedback are shown. The attenuation of vibrations is obvious. It is good to note that when no pressure feedback is used, the oscillations created from a sudden big force (step input $40 \mathrm{kN}$ ) are a long time transmitted trough the system before they are attenuated.

The analysis done in the previous passages lead to the following conclusions:

1. The implementation of the dynamic pressure feedback will damp the oscillations of the system drastically. However, it is interesting to note that simulations shown that the pick pressure has not been removed, rather in some situations it has been enlarged.

2. The draw-back of this principle is that energy from the pump must be supplied in order to damp oscillations. The pump is supplying flow to the meter out port (lower pressurized port) in order to make the system more stiff which is making this method not energy efficient.

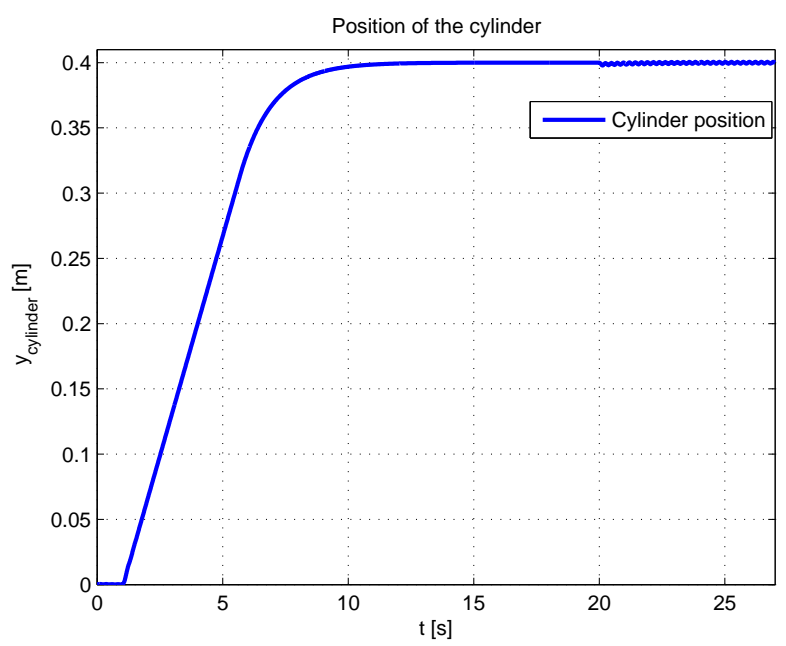

Figure 14: Cylinder position, when force is applied on a LSPC servo system (without DPF).

\section{Energy efficient active vibration damping}

In this section a novel system for active vibration damping with energy efficient dynamic pressure feedback (EE DPF) is presented. In order to damp vibrations, in the new system it is used third, crossport valve (see fig. 17 and fig. 18). Crossport valve in independent metering systems is usually introduced in order to be used for regenerative purposes as it is shown on fig. 18. When the desired moving direction is the same as the direction of a load force, than the load force can be used as a power supply element in the circuit. In this situation the cross port (third) valve is open and meter-in and meterout valves are closed (see fig. 18). The speed of the load

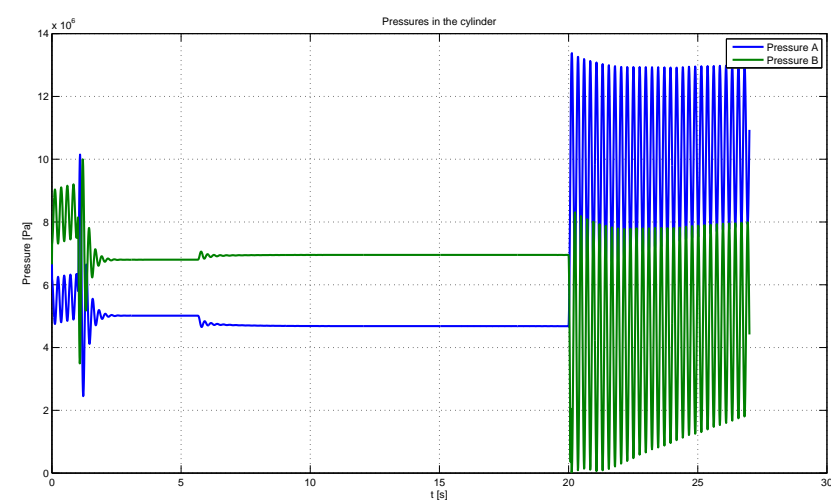

Figure 15: Pressure response without pressure feedback on meter-in side.

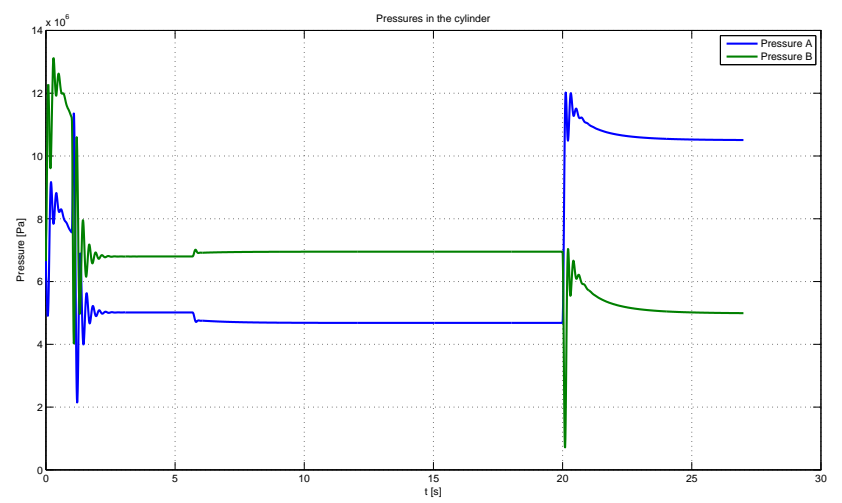

Figure 16: Pressure response with pressure feedback on meter-in side

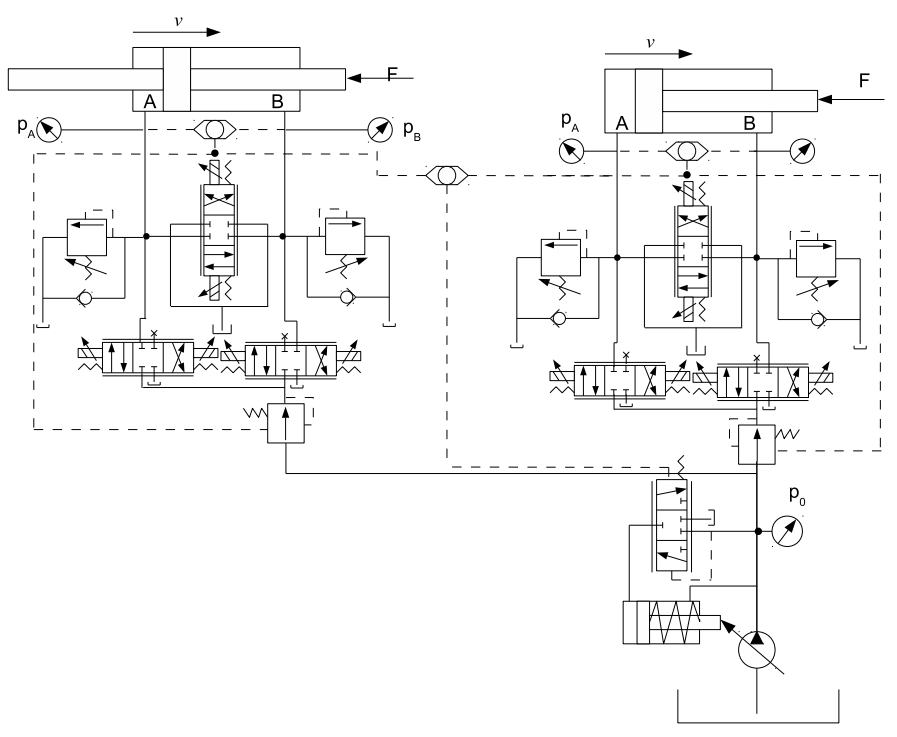

Figure 17: New SMISMO hydraulic system with cross port valve.

is then controlled with the opening of the cross-port valve. The crossport valve works in two modes of operation: (1.) Regenerative extension and (2.) Regenerative retraction.

The idea is to use this crossport valve for energy efficient (EE) active vibration damping with dynamic pressure feed- 

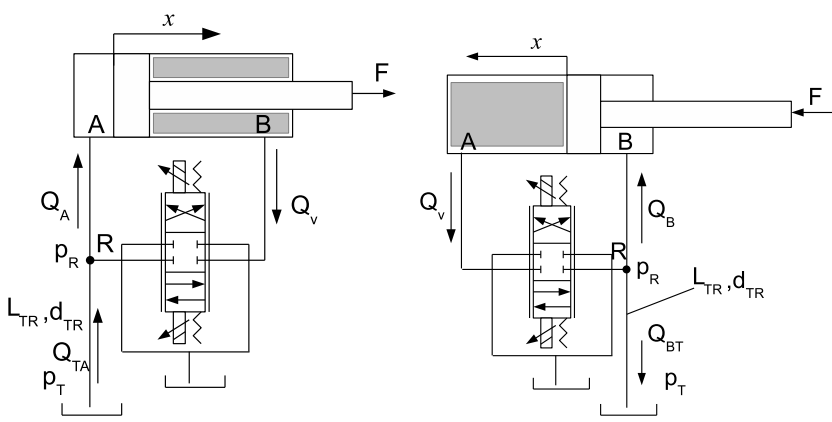

Figure 18: Regeneration with negative force (left) and regeneration with positive force (right).

back (DPF). The third valve for EE DPF can be implemented also in standard servo systems. In order to test this idea, Simulink model of the crossport valve and his controller has been developed (fig. 19 and fig. 20). Simulations have shown that the third valve can be the same type of valve as the other two valves, or with bigger nominal flow.

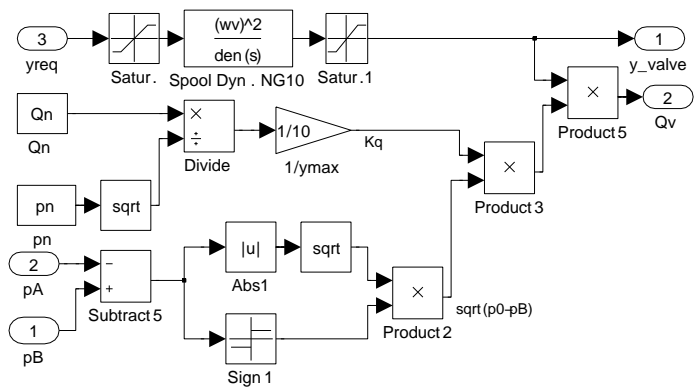

Figure 19: Simulink model of the crossport valve.

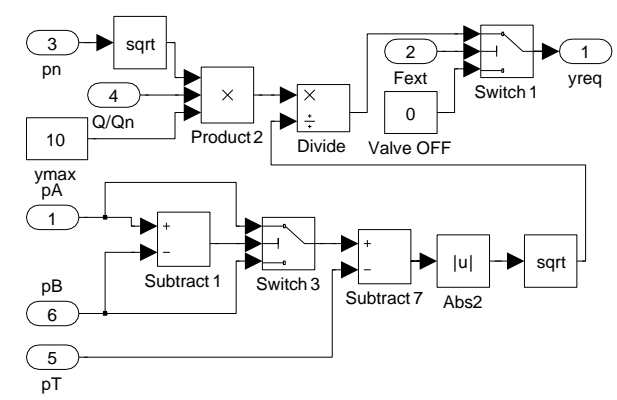

Figure 20: Simulink model of the crossport valve controller.

The following scenario has been examined: cutting head is moved using the vertical cylinder to reach $400 \mathrm{~mm}$ displacement from starting position when (in second 20) force of $50 \mathrm{kN}$ is applied in positive direction (restrictive force). The vibrations in the system are monitored trough pressure signals from the cylinder and position signals from the cylinder and cutter head. Since, power represents time derivative of work $P=\frac{d W}{d t}$ energy can be calculated integrating instantaneous power $\left(P=Q_{\text {load }} \cdot p_{\text {pump }}\right)$ over time $E=$ $W=\int P d t=\int F \cdot v d t=\int p_{\text {sup }} \cdot Q_{\text {load }} d t$. The energy spend in period of 10 seconds has been used in comparisons of the suggested strategies, since this period is enough to the system to go back in previous state before the disturbance.

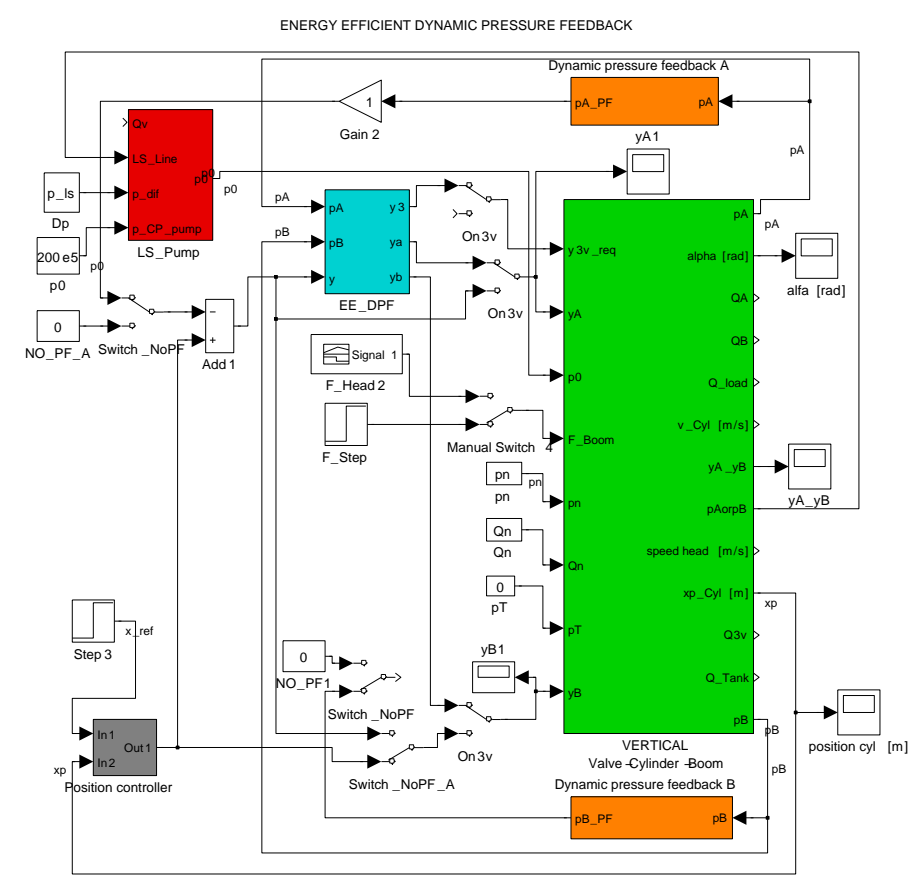

Figure 21: Simulink model of the SMISMO system. Different active damping strategies can be examined using appropriate switches.

Three strategies for active vibration damping have been examined using Simulink model shown on the fig. 21

Strategy 1. Here, DPF has been used as in classical servo systems (fig. 11 and fig. 12. Active damping with dynamic pressure feedback is implemented (only) on the piston side (high pressure side), then signal from pressure oscillations is subtracting the signal from a position controller and then supplying the valve $\mathrm{A}$ and valve $\mathrm{B}$ (meter-in and meter-out valve) with control signal. Thus, control signals of the valve $A$ and valve $B$ has been influenced from pressure oscillations. Dampening effect in this strategy will be count as best and will be used to compare Strategy 2 and Strategy 3.

On fig. 22 we can see that:

- Pressure oscillations have been attenuated very effectively and in very short period, less then $1 s$.

- Unfortunately, for this wonderful work of damping, in 10 seconds, $9840 \mathrm{~J}$ of energy have been used from the supply.

Strategy 2. In this strategy, DPF is implemented on the piston side, same as in Strategy 1 but now, crossport (3-th) valve is included in control circuit. Control signal to the valves is supplied trough EE DPF controller which decides when will be the third valve turn on. Third valve is activated when the conditions for his activation are fulfilled, actually when $p_{A}>p_{B}$ and control signal from a position controller is negative. For the simulations it is used valve with $20 \%$ bigger nominal flow than other 

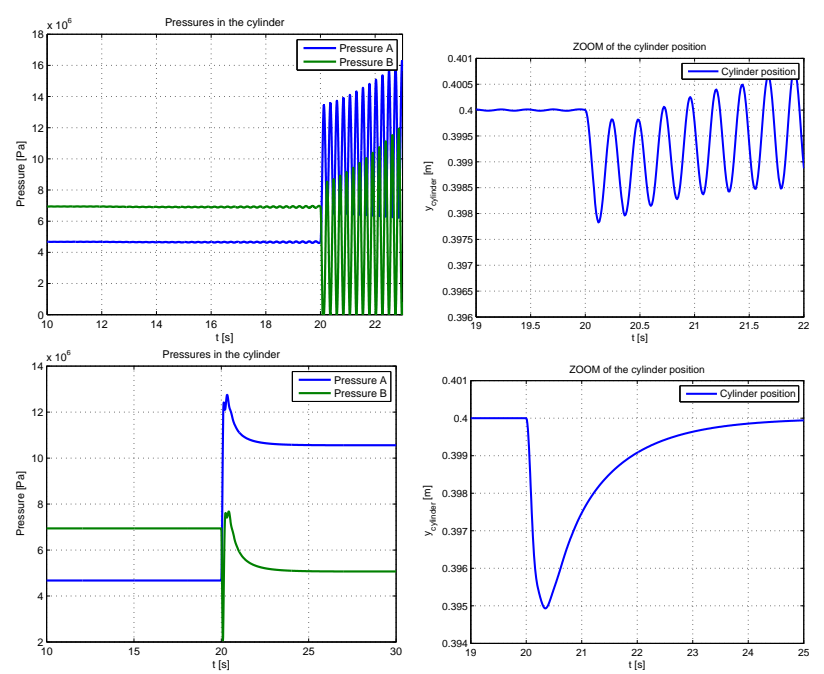

Figure 22: Cylinder pressures and position. SMISMO system without and with DPF.
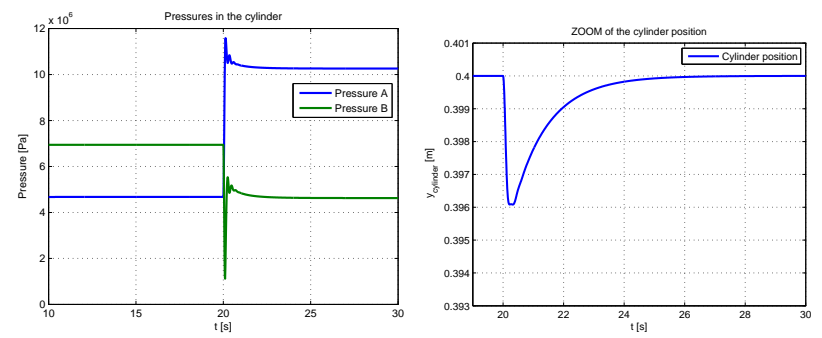

Figure 23: Cylinder pressures and position of the SMISMO system with EE DPF.

two valves, in order to get similar position footprint as in Strategy 1.

Comparing fig. 22 and fig. 23 it can be concluded that with Strategy 2 pressure and position vibrations can be successfully attenuated as well as with Strategy 1, and even better with Strategy 2, pressure in low pressure chamber is not going below 7 bars.

With this strategy for the work of vibration damping, in 10 seconds, $4818 \mathrm{~J}$ of energy have been spend from the supply. This means that Strategy 2 is $51 \%$ more energy efficient strategy for active vibration damping.

Strategy 3. In this strategy, DPF has been implemented on the piston side then signal from pressure oscillations is subtracting the signal from a position controller, then supplying to the valve A. Thus, control signal from a position controller supplied to the valve B has not been influenced. This is not unusual to be done and has been reported as control strategy in [41]. In order to get the same position footprint as in Strategy 1, the signal from DPF had to be 3 times enlarged.

Comparing fig. 22 and fig. 24 it can be concluded that with Strategy 3 position vibrations can be successfully attenuated as well as with Strategy 1. Little pressure vibrations have stayed but they are on satisfactory level. Unfortunately, with Strategy 3, pressure in low pressure
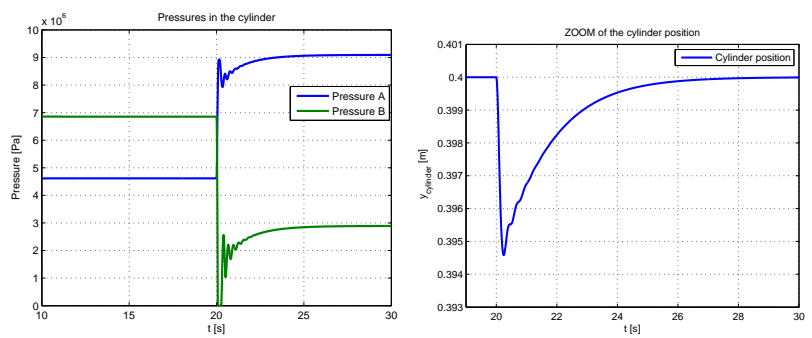

Figure 24: Cylinder pressures and position of the SMISMO system with DPF only on high pressure side.

chamber is falling deep to cavitation. For the work of vibration damping in $10 \mathrm{~s}$ with this strategy $6892 \mathrm{~J}$ have been spend from power supply.

This means that this strategy has better energy efficiency than Strategy 1 (30\%), but one must have in mind that with this strategy pressure control on a low pressure side must be implemented. This strategy can not be implied in standard servo systems.

\section{Conclusion}

Research done in this paper had intention to investigate possible improvements in a hydraulic power system of a mobile machine (mining machine), hydraulic system layout and control strategy, and with this contribute to better vibration damping of the machine.

Investigations has been done using simulations and measurements. Appropriate models of the standard and individual metering load sensing (LS) hydraulic system have been developed. Model of the individual metering system has been validated with measurements. This model has been used to study new control concepts of active vibration damping.

As a result from those investigations, innovative system layout with three independent metering valves has been proposed. The third valve (called also crossport valve) is introduced in order to improve active vibration damping.

The idea to use this crossport valve for active vibration damping with dynamic pressure feedback (DPF) proved to be energy efficient concept. In investigations three strategies has been compared, in first an standard dynamic pressure feedback has been used, in second DPF on only one valve has been used and in third DPF with third valve has been used. Novel concept and control strategy of DPF with third valve proved to be superior in comparison with the other two methods according to their energy efficiency and damping. In comparison, energy efficiency of the novel concept proved potential for $50 \%$ savings with same or better damping effect.

\section{References}

[1] J. Hosseini. Automatic ride control, 1992.

[2] S.T. Ufheil et al. Programmable ride control, 1996.

[3] P. Krus and J.O. Palmberg. Dampening of fluid power systems in machines with high inertia loads. In Proc. SICFP, Sweden, 1998. 
[4] S. Mizui et al. Device and method for suppressing vibration of a working machine, 1998.

[5] K. Moon. Control system for suppression of boom or arm oscillations, 2007.

[6] K. Yoshino. Vibration control method and vibration control system for fluid pressure control circuit, 2007.

[7] A.D. Borger et al. Electronic ride control system for off-road vehicles, 1999.

[8] Lei Zuo et al. Model reaching adaptive control for vibration isolation. 13(4), 2005.

[9] Lei Zuo, Jean-Jacques, and E. Slotine. Robust vibration isolation via frequency-shaped sliding control and modal decomposition. 2005.

[10] I. Fialho et al. Road adaptive active suspension design using linear parameter-varying gain-scheduling. 10(1), 2002.

[11] Toni Liedes. Improving The Performance Of The SemiActive Tuned Mass Damper. $\mathrm{PhD}$ thesis, Univ. of OULU, Finland, 2009.

[12] Jyh-Chyang Renn and Tsung-Han Wu. Modeling and control of a new 1/4t servo-hydraulic vehicle active suspension system. 15(3), 2007.

[13] C. A. Pare. Experimental evaluation of semiactive magneto- rheological suspensions for passenger vehicles. Master's thesis, Virginia Polytechnic Institute and State University, Virginia, 1998.

[14] Mark D. Donahue. Implementation of an active suspension, preview controller for improved ride comfort. Master's thesis, B.S. Boston University, Boston, US, 1998.

[15] Yuyou Liu. Semi-Active Damping Control For Vibration Isolation Of Base Disturbances. PhD thesis, University of Southampton, Southampton, UK, 2004.

[16] K.S. Hon et al. Modified skyhook control of semiactive suspensions: A new model, gain scheduling, and hardware-in-the-loop tuning. In Proc. of ASME, 2002.

[17] A. Preumont. Active Vibration Control. Lecture Notes in Active Vibration Control. University Libre de Bruxelles, Brussels, Belgium, 2000.

[18] T.K. Datta. A state-of-the-art review on active control of structures. 40(1), 2003.

[19] Kan Shimizu, Toshikazu Yamada, Jun Tagami, and Haruhiko Kurino. Vibration tests of actual buildings with semi-active switching oil dapmer. In Proc. of 13th World Conference on Earthquake Engineering, Vancouver, B.C., Canada, 2004.

[20] H. Ivanov et al. Optimal control of electrohydraulic power transmission. In International summer scool of automation, Maribor, Slovenia, 2001.
[21] J. Leavitt, F. Jabbari, and J. E. Boborw. Optimal control and performance of variable stiffness devices for structural control. In Proc. of the American Control Conference, Portland, OR, USA, 2005.

[22] P. Holobut. Time-optimal control of hydraulic manipulators with path constraints. 43:523-538, 2005.

[23] J.A. Aardema et al. Systems and method for controlling an independent metering valvel, 1999.

[24] B. Eriksson. Mobile Fluid Power Systems Design with a Focus on Energy Efficiency. PhD thesis, Univ. of Linkoping, Linkoping, Sweden, 2010.

[25] B. Eriksson. Control strategy for energy efficient fluid power actuators utilizing individual metering. Master's thesis, Univ. of Linkoping, Linkoping, Sweden, 2007.

[26] K. Heybroek. Saving energy in construction machinery using displacement control hydraulics-concept realization and validation. Master's thesis, Univ. of Linkoping, Linkoping, Sweden, 2009.

[27] Q.H. Yuan and Jae Y. Lew. Modeling and control of two stage twin spool servo-valve for energy-saving. In American Control Conference, Portland, OR, USA, 2005.

[28] B.S. Turner. Electrohydraulic proportional valve assemblies, 1996.

[29] B. Yao and S. Liu. Energy-saving control of hydraulic systems with novel programmable valves. In Proc. of the 4th World Congress on Intelligent Control and Automation, Shanghai, P.R. China, 2002.

[30] S. Liu and B. Yao. Energy-saving control of single-rod hydraulic cylinders with programmable valves and improved working mode selection. In Proc. of the NCFP, 2002.

[31] J.A. Crosser. Hydraulic circuit and control system therefor, 1992.

[32] T. Hajek et al. Hydraulic system with an actuator having independent meter-in meter-out control, 2005.

[33] C.Dixen and B. Nielsen. Hydraulic valve arrangement, 2006.

[34] M. Linjama and M. Vilenius. Energy-efficient motion control of a digital hydraulic joint actuator. In Proceedings of the 6th JFPS International Symposium on Fluid Power, SUKUBA, 2005.

[35] B. Eggers, R. Rahmfeld, and M. Ivantysynova. An energetic comparison between valveless and valve controlled active vibration damping for off-road vehicles. In Proc. Symposium on Fluid Power, TSUKUBA, 2005.

[36] Sandvik Mining and Construction G.m.b.H., Sandviken, Sweden. Sandvik Tunneling Roadheader MT720 in Action, 2009. 
[37] E. Zaev, G. Rath, A. Tuneski, and D. Babunski. Nonlinear modeling and hil simulation of hydraulic cylinder for hydro turbine governing system. In Proc. ZEMAK2010, Ohrid, Macedonia, 2010.

[38] W. J. Thayer. Transfer Functions for Moog Servovalves. Moog Inc., East Aurora, NY, 1965.

[39] P. Krus. On Load Sensing Fluid Power Systems with Special reference to Dynamic Properties and control Aspects. PhD thesis, Univ. of Linkoping, Linkoping, Sweden, 1988.

[40] H.C. Pedersen, T. O. Andersen, et al. Investigation of separate meter-in separate meter-out control strategies for systems with over centre valves. In Proc. FPMC2010, 2010.

[41] T. O. Andersen. Evaluation of velocity control concepts involving counter balance valves in mobile cranes. In Proc. IEEE, 2008. 